\title{
The use and performance of survey-based pre-recruit abundance indices for possible inclusion in stock assessments of coastal-dependent species
}

Le Pape Olivier ${ }^{1,{ }^{\star}}$, Vermard Youen ${ }^{2}$, Guitton Jerome ${ }^{1}$, Brown Elliot J. ${ }^{3}$, Van De Wolfshaar Karen E. ${ }^{4}$, Lipcius Romuald N. ${ }^{5}$, Stottrup Josianne G. ${ }^{3}$, Rose Kenneth A. 6

${ }_{1}^{1}$ Agrocampus Ouest, ESE, INRAE, Ecol \& Ecosyst Hlth, F-35042 Rennes, France.

2 IFREMER, Ecol \& Models Fisheries Sci, EMH, Plouzane, France.

3 Tech Univ Denmark, Natl Inst Aquat Resources DTU Aqua, Kemitorvet,Bldg 202, DK-2800 Lyngby, Denmark.

${ }^{4}$ Wageningen Marine Res Ecol Dynam Grp, NL-1970 AB ljmuiden, Netherlands.

5 Virginia Inst Marine Sci, William \& Mary, POB 1346, Gloucester Point, VA 23062 USA.

6 Univ Maryland, Ctr Environm Sci, Horn Point Lab, POB 775, Cambridge, MD 21613 USA.

* Corresponding author : Olivier Le Pape, email address : olivier.le.pape@agrocampus-ouest.fr

\begin{abstract}
:
We reviewed the use of survey-based pre-recruit abundance indices in short-term recruitment forecasts for fish species relying on coastal habitats at the juvenile stage and that are assessed by ICES. We collated information from stock assessment reports and from a questionnaire filled out by the stock assessors. Among the 78 stocks with juvenile coastal dependence, 49 use short-term forecasts in stock assessment. Survey-based pre-recruit abundance indices were available for 35 of these stocks, but only 14 were used to forecast recruitment. The questionnaire indicated that the limited use of survey-based pre-recruit abundance indices was primarily due to sampling inefficiency, which may preclude reliable recruitment estimates. The sampling is inefficient because the juvenile coastal distribution is outside the geographical area covered by large-scale surveys or targeted coastal surveys are conducted on limited spatial and temporal scales. However, our analysis of the relationship between survey-based pre-recruit indices and assessment-generated recruitment indices revealed that survey-based pre-recruit abundance indices were sufficiently accurate to provide useful information for predicting future recruitment. We recommend expansion of the use of survey-based indices of pre-recruit abundance in stock assessment and recruitment forecasting, and consideration of how to include juveniles in ongoing and future surveys.
\end{abstract}

Keywords : coastal nursery, forecast, juvenile habitat, recruitment, stock assessment, survey 


\section{Introduction}

Recruitment variability of many marine and coastal fish species is the main driver of

43 fluctuations in population abundance and critically depends on the highly variable mortality

44 rates of early life stages (Levin and Stunz, 2005; Juanes, 2007; Archambault et al., 2014).

45 Forecasting future recruitment has long been a focus of fisheries management (Hilborn and

46 Walters, 1992; Needle, 2001) and continues to be an essential part of evaluating fishery

47 management strategies (Kimoto et al., 2007; Stige et al., 2013; Punt, 2019). Stochastic

48 processes that occur at the egg and larval stages generate high mortality rates (typically $99.9 \%$

49 for eggs and larvae; Le Pape and Bonhommeau, 2015), which can also be density-dependent

50 and can vary greatly from year-to-year, thereby generating large fluctuations in recruitment 
(Houde, 2008; Cury et al., 2014; Szuwalski et al., 2015). Accordingly, egg and larval abundances estimated from ichthyoplankton surveys are often poorly correlated to future recruitment success. In contrast, after a "critical" stage or size (Cowan et al., 2000; Dingsor et al., 2007; Houde, 2008), juvenile fish experience considerably lower and more consistent mortality rates than eggs and larvae. Abundance, whether absolute or relative (index), can be estimated during the juvenile stage for many species (Le Pape and Bonhommeau, 2015), without major discrepancies arising from the highly variable mortality rates typical of earlier life stages. In stock assessment, pre-recruitment is considered the life stage after the transition from the highly variable early stages (eggs, larvae, and often early juveniles) to when natural mortality is largely stable (Lorenzen and Camp, 2019) but before individuals fully join the adult stock. Survey-based pre-recruit abundance indices could therefore provide reliable information on recruitment and future year-class strength (Helle et al., 2000; Zhang et al., 2010; Stige et al., 2013).

Indices estimating pre-recruit abundance can provide projections of recruitment and can inform fisheries management, especially for stocks whose exploitation is highly dependent on the juvenile stage. Such stocks depend on recruitment for determining harvest, due either to their biology (short-lived species, like small pelagics) or because high exploitation rates reduce the age of the fish harvested. For example, high exploitation rates of Atlantic cod Gadus morhua in the North Sea during the last five years (2012 to 2016) of the assessment resulted in immature fish constituting an average of $71 \%$ of the international landings in number (ICES, 2017c).

Coastal zones are biologically productive areas that serve as juvenile habitat for numerous marine species (Beck et al., 2001). For example, considering the species for which ICES provides advice, one-third are dependent on coastal habitats during their juvenile stage (Seitz et al., 2014), and these species account for $66 \%$ of the total landings of ICES-evaluated stocks (Brown et al., 2018a). Scientific surveys at the population scale are usually designed to estimate 
density and age-structure of post-recruited fish. Many surveys focus on post-recruitment fish for specific management purposes and therefore are not designed nor appropriate for estimating pre-recruit abundance. Additionally, such post-recruitment surveys most often do not provide adequate coverage of coastal habitat on which juveniles rely (Ralph and Lipcius, 2014). When juveniles aggregate in coastal areas, survey designs that cover suitable shallow coastal habitats are required to produce reliable estimates of pre-recruit density. The timing within the year of the surveys is also important to give sufficient time for the recruits to settle in the juvenile habitats and to pass the early juveniles stages that incur highly variable survival (van der Veer, 1986; Wennhage, 2002; Nash et al., 2007). Surveys designed for other purposes may not cover the time period that is optimal for estimating recruitment from pre-recruits. Even when the surveys focus on juveniles before recruitment, they tend to be spatially localized, thereby creating challenges to extrapolate the results to the broader spatial domain of the managed stock. A valid reason for why surveys are not used to generate pre-recruit indicators is simply that the surveys were well designed for other purposes and provide insufficient coverage of the spatial and temporal scales of the juveniles (Albert et al., 2001; Ralph and Lipcius, 2014).

This paper focuses on the use of survey-based pre-recruit abundance indices and the degree of agreement between survey-based and stock assessment estimates of annual recruitment for species with juvenile coastal dependence. Accurate short-term forecasts of recruitment could improve the management advice in the stock assessment of species with juvenile coastal dependence. We focused on those ICES-assessed species whose juveniles rely on coastal habitats (see definitions in Seitz et al., 2014) and reviewed the use of survey-based pre-recruit abundance indices for short-term forecasts. For all ICES-assessed stocks whose juveniles use coastal habitats, we collated information from stock assessment reports and from a complementary questionnaire, which we designed for completion by the lead fisheries scientist for each stock assessment. The goals of our analysis were to: (1) assess the frequency 
of the use of survey-based pre-recruit abundance indices in recruitment forecasts in the framework of ICES stock assessment working groups; (2) identify factors that influence when survey-based pre-recruit abundance indices are used; (3) determine the level of accuracy (agreement with stock assessment estimates) when survey-based pre-recruit abundance indices are used to indicate recruitment; and (4) suggest possible factors that influence the accuracy of the survey-based estimates. Our focus was on goals (1) and (3) because we had relatively high confidence in the underlying information and they provide important results about the frequency of use of pre-recruit surveys and their overall performance. The reliability of information to achieve goals (2) and (4) was uncertain, as it is difficult to judge a survey program for generating pre-recruit information when the survey was designed for other purposes (goal 2) and our sample size of surveys was too small for assessing which factors influence accuracy (goal 4).

\section{Methods}

\section{Data collection}

Of the 61 species for which ICES carried out stock assessments in 2017 and 2018, 18 species (Table 1) had juveniles with coastal dependence (Seitz et al., 2014). These 18 species encompass 78 distinct stocks. Information about the use of survey-based pre-recruit abundance indices for these ICES-assessed 78 stocks was collated. The information came from the ICES stock assessment working group (WG) reports (ICES, 2017a-c; ICES, 2018a-f), and the questionnaire completed by the lead fisheries scientists in charge of each stock assessment. The ICES WG reports, questionnaire responses, and follow-up communications with WG members provided the following information on the 78 stocks that rely on coastal habitat:

1. ICES DLS (data-limited stocks) category (ICES, 2012). The categories spanned from DLS category 1 (data-rich stocks with quantitative assessments) to DLS category 3 (stocks for 
which survey-based assessments indicate trends) to categories DLS 4-6 (data-poor stocks without quantitative assessments).

2. Whether pre-recruit surveys were used for short-term estimation and prediction of recruitment. In ICES stock assessment WG terminology, recruitment estimation means projecting the youngest assessed year class strength for years $y$ and $y+1$. The term recruitment prediction is used in WGs to calculate TAC advice when recruitment is projected two years ahead. In the present analysis, we pooled these two situations and considered the use of pre-recruit surveys both for recruitment estimation or prediction (hereafter called "short-term forecasts of recruitment"). Performing recruitment estimation is the minimum required and is mandatory for DLS category 1, but is highly unusual for the other categories.

3. Availability of survey-based abundance estimates for pre-recruits. The expertise of the lead fishery scientist involved with the assessment was the key source for these estimates. Indeed, WG reports only mention survey-based abundance indices when used in stock assessment. When they are not accounted for, expertise is the only means to investigate whether such indices exist.

4. When used, how were the short-term survey-based pre-recruit abundance indicators combined with the stock assessment? Survey-based pre-recruit abundance indices are typically used in two ways in ICES stock assessments: (i) post-hoc short-term forecasts of year-class strength by calibration-regression analysis of recruit index series (e.g., RCT3; Shepherd, 1997) and then used to account for future recruitment after a matrix model-based stock assessment is completed (e.g., Extended survivors analysis, XSA; Shepherd, 1999); or (ii) state-space modeling (e.g., SAM; Nielsen and Berg, 2014) that integrates the surveybased pre-recruit abundance indices directly into a stock assessment. We analyzed both uses of survey indices. 
When survey-based pre-recruit abundance was available as an index (positive response to item 3 above), additional information was collated for that subset of stocks:

5. Sampling gear (i.e., acoustic, trawl or net) used in the survey to derive the pre-recruit index.

6. Spatial scale of the survey as one of four possibilities: (i) stock scale that included juvenile habitats; (ii) stock scale that did not include juvenile habitats; (iii) stock spatial distribution partially covered with the area covered including juvenile habitats; and (iv) stock distribution partially covered and juvenile habitats not sampled.

7. Average number of samples in the annual survey.

8. Age-group represented in the survey-based recruitment estimate and the youngest age-group included in the stock assessment.

Finally, when responses indicated that a stock assessment included short-term forecasts of recruitment and a pre-recruit survey was available but not used to forecast recruitment:

9. The fisheries scientist for that stock assessment was asked why the survey was not used. Four possible responses were offered in the questionnaire: (i) the pre-recruit index time series was incomplete; (ii) the pre-recruit survey was carried out too late in the year to be available for the ICES stock assessment working group; (iii) the potential use of the survey-based prerecruit abundance indices had not been evaluated; or (iv) pre-recruit survey-based indices were investigated (e.g., during the benchmark procedure) but a decision was made to exclude them from analysis.

Analysis: Availability and use of survey-based pre-recruit abundance indices for short-term

forecasting in assessment

The frequency of the use of short-term forecasts of recruitment in stock assessment, and the availability and the use of survey-based pre-recruit abundance indices to forecast recruitment, were estimated from the WG reports and questionnaires collated for each stock. 
175 Starting with the 78 (18 species) ICES-assessed stocks, we categorized these by habitat 176 (demersal, benthic, pelagic). These stocks were further subdivided into those that used short-

177 term forecasts in their assessments and either did or did not use available pre-recruit surveybased indices. For the subset of stocks that did not use the survey-based pre-recruit indices, the reasons for disuse by the WG assessors were noted. Another subset of stocks, that relied on short-term recruitment forecasts and also used pre-recruit survey results to generate short-term forecasts, was further analysed for accuracy of the survey-based predictions.

Analysis: Accuracy of survey-based pre-recruit abundance indices to forecast recruitment

Time series of survey-based recruitment predictions were obtained from ICES WG reports for each of the stocks that used survey-based pre-recruit indices for forecasting shortterm recruitment in the assessment (ICES, 2017a-c; ICES, 2018a-f). For these stocks, time series of model-based recruitment short-term forecasts were obtained from the ICES database (ICES, 2018g). Complementary analyses were performed to assess the potential for autocorrelation between survey-based and model-based short-term forecasts of recruitment, because for some stocks the survey was also used within the assessment. When survey-based pre-recruit abundance indices were not used in the stock assessment modelling, but rather to make short-term forecasts post-assessment, the survey-based and stock-assessment-based indices were inherently independent and could be directly compared. However, when the survey-based pre-recruit abundance indices were used within the stock assessment, they influenced the assessment-based recruitment indices and could result in artificial agreement between the two short-term forecasts of recruitment because they were no longer independent. Two alternative options were used to reduce or to remove this potential for artificial agreement between the two short-term forecasts (survey and assessment) of recruitment: (1) elimination of the last two years from the analysis, and (2) re-run of the stock assessment 
without the survey index included to generate assessment-based recruitment not influenced by the survey results:

- The influence of survey results on assessment-generated estimates of recruitment can be significant, especially for the last years in a stock assessment (Hilborn and Walters, 1992). The influence of the survey results diminishes over time, as other sources of information in the stock assessment (e.g., catch-at-age and survey data on the older ages) inform the estimated recruitment values. To partially account for dependence between the survey- and model-based estimates, we eliminated the last two years of recruitment estimates for those stocks that used the survey-derived estimates as part of their stock assessment modeling. This elimination was done either manually or because the last two years were dropped when matching the two recruitment indices (i.e., there were no survey estimates available to match recruitment for the last two years of the assessment). To test the robustness of these modelling option, we employed two methods, both of which focus on the accuracy of the correlation results from stocks that used survey indices in their assessments: The first was a comparison between the four stocks with independent survey and assessment estimates of recruitment and the remaining 10 stocks that included the survey index in their assessment. The second was a windowing approach to compute correlations between survey and assessment estimates of recruitment, to assess the influence of the last years in correlations (see details in supp. Mat. 2).

- The best way to address this potential for artificial agreement is to re-run the stock assessments without the survey-derived indices, and then compare the new assessment-based estimated recruitments with the, now independent, survey-derived estimates of recruitment. Such an approach is obviously the most attractive in theory, but each assessment varies among the different stocks and cannot been tuned from the ICES database without the expertise of the stock assessment WG. To do so, the fisheries scientists in charge of these stock assessments were asked to re-run the stock assessments without the survey-derived indices, and some of 
them kindly did so. These new time series of model-based recruitment were collated and used separately from the potentially correlated estimates in analyses. This subset of comparisons allowed us to evaluate the robustness of results based on the potentially correlated estimates. For standardization purpose, we also eliminated the last two years of the recruitment estimates from these series, either manually or naturally.

To assess the accuracy of the survey-based predictions of recruitment compared to assessment-based estimates, we computed the Pearson correlation coefficient $(r)$ between the survey-based recruitment estimates and the stock assessment model-based abundance for the youngest year group. This was done for all stocks ( $\mathrm{r}_{1}$, using model-based data from ICES database) and for the subset of 10 stocks that the assessment estimates were independent of the survey ( $\mathrm{r}_{2}$, from stocks whose assessment did not use survey or from re-run assessment models). We assumed that the model-based estimates were a realistic value and thus the closer the correlation of the survey-based prediction to the model-based value, the higher the accuracy of the survey-based value. Because the true value of recruitment is unknown, we refer to this as apparent accuracy. While agreement between the two estimates of recruitment suggest higher confidence in the survey-based estimates, without knowing the true values of recruitment we cannot access whether either is or both are biased.

For the stocks for which correlation coefficient $r_{1}$ (model-based data from ICES database) and $r_{2}$ (for rerun assessment estimates) were available, we first compared their respective levels to highlight potential lack of independence and caution about interpretation of $r_{1}$. From this preliminary analysis ( $r_{1}$ versus $r_{2}$ for rerun stocks only), we determined if we would use the $r_{2}$ values (truly independent estimates on 10 stocks) rather than the $r_{1}$ (14 stocks but only 4 trully independent estimates only) in subsequent analyses.

Another proxy $\left(r_{3}\right)$ was designed to approximate how short-term recruitment forecasts can be used in stock assessments that do not have a source of year-specific short-term forecasts. 
The geometric mean of the model-based abundances for the youngest year class during the previous five years was computed. When year-specific forecasts of recruitment are not used, geometric mean of model-based recruitment estimates is frequently used in forecasting for ICES stock assessments. To estimate the improvement of the forecast linked to the use of survey-based pre-recruit abundance indices, $r_{1}$ or $r_{2}$ and $r_{3}$ were compared. We used a one-way analysis of variance (ANOVA), after an arcsine transformation, to compare $r_{1}$ or $r_{2}$ to $r_{3}$ values. The arcsine transformation is appropriate to normalize the data from the original $[-1,1]$ distribution of correlation coefficients (Sokal and Rohlf, 1995). A higher value of $r_{1}$ or $r_{2}$ (for the survey-based estimates) compared to $r_{3}$ (geometric mean of the assessment-based estimates) indicates that survey estimates agree with assessment values better than average recruitment agrees with the assessment values. In this way, $r_{3}$ is an approximate proxy of the contribution of survey-based pre-recruit indices to estimate future recruitment over and above the use of a 5-year average.

We explored whether various factors influenced the magnitude of $r_{1}$ or $r_{2}$, including species vertical guild (Table 1), sampling gear, scale of the survey, number of samples in the survey, age group in the survey-based pre-recruit abundance indices, youngest age group in the stock assessment, difference between these two ages, and length of the time series.

\section{Results}

\section{Stocks of coastal dependent species}

ICES performed stock assessments for 185 stocks in 2017-2018 that spanned 61 species. Eighteen of these species (30\%), which involved 78 stocks (42\%), depend on coastal juvenile habitat (Table 2; supp. Table 1). These 78 stocks are widespread in the North East Atlantic (from Iberian waters to Greenland in latitude and from the North Sea to Greenland in longitude) and in the Baltic Sea (supp. Table 1). The habitat use of these species and stocks with juvenile 
coastal dependence were: demersal ( 9 species; 39 stocks), benthic ( 6 species; 23 stocks), and pelagic ( 3 species; 16 stocks). Among these 78 stocks, most (87\%) were well-assessed stocks (ICES categories 1 and 3), whereas 10\% were data-poor stocks, all of which were demersal species (supp. Table 1).

Use of recruitment forecasts and pre-recruit surveys in assessment

Among the 78 stocks from species with juvenile coastal dependence, 49 (Table 2) used short-term recruitment forecasts (from any source) in their assessments. Most of these 49 stocks (46) were designated as DLS Category 1, with the remaining three stocks being DLS 3. Surveybased pre-recruit abundance indices were available (used and not used in the assessment) for $35(71 \%)$ of these 49 stocks, which were all designated as DLS Category 1 (Table 2; Figure 1). For these 35 (of 78) stocks with both survey-based pre-recruit abundance indices available and that use short-term recruitment forecasts in their assessment (Table 2), the pre-recruit indices were derived mainly (supp. Table 1) from trawl surveys for demersal species (12 of 18 stocks) and benthic species ( 9 of 9 stocks), and from acoustic surveys for pelagic species ( 5 of 8 stocks). While survey-based pre-recruit abundance indices were available for 35 of the 49 stocks that generated recruitment forecasts in their assessments, only 14 of these 35 stocks (40\%; Table 2; Figure 1) actually used the indices in their assessments. For the majority of stocks (21 of 35), the indices were not used for short-term forecasts of recruitment. The underutilisation of surveybased indices was noteworthy for stocks of demersal species (12 of 18 stocks did not use the indices; supp. Table 1).

Six stocks with unused indices reported that the available time series were not yet sufficient or because the results would not be available in time for consideration by the WG (Table 3). But, the most commonly reported reason for not using the survey-based indices (11 of 21) was that the use of the indices had not been thoroughly evaluated (Table 3; supp. Table 
1). The remaining four stocks with unused indices had attempted to use the indices but a decision was made to not use them because the surveys were not designed to estimate prerecruit abundance in the spatial domain of the stock (Table 3). A partial explanation for not using the survey-based indices when they were sufficient and available (15/21) was that these surveys were not designed to cover both the spatial scale of the stock and/or coastal juvenile habitats (Table 3).

Fourteen stocks used the survey-based pre-recruit indices in their forecasts. These 14 stocks are distributed in the North East Atlantic (from Bay of Biscay to Greenland in latitude and from the North Sea to Greenland in longitude) and in the Baltic Sea (Table 4). For these 14 stocks, seven of the indices were derived from surveys covering both the stock scale and coastal nurseries, four indices were from surveys that partially cover the stock's spatial extent and include coastal nurseries, and three indices were calculated from surveys done at the stock spatial scale but which do not include coastal juvenile habitat (Table 4).

Apparent accuracy of survey-based pre-recruit indices

For 12 of 14 stocks (Table 4), pre-recruit abundance indices were used in the assessments. These were either derived from a single survey ( 8 stocks,) or were combined into a single recruitment index as part of the assessment by the ICES working group (4 stocks, North Sea cod and sole, Irish Sea plaice and Celtic Sea whiting; ICES, 2017c). Two (of 14) stocks used two survey-based pre-recruit abundance indices for short-term forecasting (Table 4): Iceland cod (ICES, 2018c) and North Sea whiting (ICES, 2017c). Our analysis of the relationship between the survey-based pre-recruit abundance indices and the model-based abundance for the youngest year class $\left(r_{1}\right.$ and $\left.r_{2}\right)$ considered a single survey-based pre-recruit (Miethe, pers. com.) for the stock assessment (ICES, 2017c) indicated that the index in Autumn 
(IBTSQ3) is considered as the reference pre-recruit abundance index. For Iceland cod, we initially analysed both indices separately (surveys SMB and SMH had correlation coefficients of 0.75 and 0.8 with model-based indices, respectively); given the similarity of the results, the SMH index derived from the fall survey was selected (Table 4).

Among these 14 stocks, four use survey-based pre-recruit abundance indices only for forecasting and 10 used these indices in both stock assessment and forecasting (Table 4). Of these 10, only five required manual deleting of two recent years. The other five stocks, which used the survey indices in their assessments, had sufficient lag between the age of fish in the survey and the age of recruitment (youngest age) in the assessment. This meant that the two most recent years of recruitment from the stock assessment would not be auto-correlated with their survey index for our comparisons (i.e. "Natural removal", Table 4).

From the 10 stocks utilising survey-based indices in both stock assessment and forecasting, fisheries scientists in charge of assessments agreed to rerun the stock assessments without the survey-derived indices for six stocks (Table $4, r_{2}$ in bold). For these stocks, correlations were higher for $r_{1}$ than for $r_{2}$ (Table 4 , for the 6 stocks, average difference in Pearson correlation coefficient $\left.r_{1}-r_{2}=0.077[0,0.19]\right)$. These patterns confirmed the preliminary tests of robustness on the use of the correlation between the survey-based recruitment estimates and the stock assessment model-based abundance; i.e., low to moderate influence of autocorrelation when the last two years of the recruitment estimates are removed (detailed in supp. Mat. 2). However slight, these differences did indicate an overestimation of $\mathbf{r}_{1}$ through correlation induced by inclusion in the assessment. Hence, we selected $r_{2}$ for further analyses, which reduced the number of stocks to 10 (4 whose assessment did not use the index and 6 rerun assessments, Table 4).

When used, the survey-based predictions of recruitment $\left(r_{2}\right)$ had a reasonable apparent accuracy (Table 4; Figure 2; Figure 3). Survey-based pre-recruit abundance indices had 
significantly higher correlations with the model-based recruitment estimates than the geometric means of the five previous years of model-based abundances (Figure $3 ; p<0.001$, after arcsine transformations of $r_{2}$ and $r_{3}$ ). No obvious patterns emerged from the factors (species habitat, survey design, Table 4) that could influence the accuracy of the survey-based pre-recruit abundance indices $r_{2}$, although the small size of the data set and the many potential influential factors made identification of associations difficult.

\section{Discussion}

We examined ICES-assessed stocks that both utilize coastal areas as juvenile habitat and use survey-based predictions of recruitment in their management assessments. Of the 78 stocks involving 18 species with juvenile coastal-dependence, 49 also used short-term forecasts of recruitment in assessments. Most of these stocks (46 of 49) were designated as ICES DLS Category 1 stocks. Indeed, short-term forecasts of recruitment are mandatory in the ICES protocol for this category. We analysed the existence and aspects of surveys and derived surveybased pre-recruit indices and how they are presently used in assessments for the 78 stocks, using data collated from WG reports, responses to a questionnaire from the lead fishery scientists for each stock, and communications with lead members of various stock assessment WGs. We sought to explore how surveys are used to generate recruitment indices as part of assessments, possible reasons for their omission, and the accuracy of predicted recruitment from surveyderived values.

The responses to the questionnaire as to why the survey information was available but not used (i.e., survey data on pre-recruit abundance were not used for $21 / 35=60 \%$ of the stocks for which they are available) indicated that there are opportunities for determination of how the survey information, either as is or with some adjustments to the survey design, could be used in assessments. The most common response for why an available survey was not used was that 
375 its utility had not been rigorously evaluated, followed by issues of whether enough data were available and that the survey results were not available in time for assessments. These three reasons accounted for why 17 of 21 stocks were not using available surveys to forecast recruitment for assessment, and suggest that surveys are available that, with proper evaluation, may be useful for generating recruitment indices.

Fishery-independent surveys are designed to answer specific questions and their lack of use for other purposes is not indicative of a poorly designed survey. For our proposed use, to forecast recruitment, the coverage of coastal habitats and the effective sampling of pre-recruit juveniles are critical. Both the stocks that did not use surveys to predict recruitment and those that did confirmed the (perhaps obvious) importance of the spatial scales of the surveys. Half of the survey-based pre-recruit indices used in assessments covered both the stock scale and coastal juvenile habitat, while the other half covered either stock scale or juvenile habitats. In contrast, none of the unused survey-based pre-recruit abundance indices covered both the stock scale and the coastal juvenile habitat. Most (87\%) of the unused pre-recruit abundance surveybased indices covered only a fraction of the spatial extent of the stock, and $47 \%$ did not sample coastal juvenile habitat.

A major challenge for estimating pre-recruit abundance indices from surveys is to account for complex spatial and temporal variation in pre-recruit abundance (Denson et al., 2017; Potts and Rose, 2018). Variation in abundance across successive juvenile stages could be driven by small scale processes, leading to large spatial discrepancies among juvenile habitats (Scharf, 2000). The temporal (including inter-annual) variability in coastal habitat use of juvenile fish suggests that to estimate recruitment, it is necessary to survey several juvenile habitats (Chittaro et al., 2008). Both juvenile coastal distributions outside the geographical area covered by the surveys and regional patterns in recruitment variability (Denson et al., 2017) 
may hinder estimation of reliable recruitment estimates (Albert et al., 2001; Ralph and Lipcius, 2014).

The 17 stocks with available surveys not being used and which have not been evaluated for use would need to be evaluated. The evaluation should consider whether the sampling design can generate sufficiently accurate predictions of recruitment, and how easy it would be to maintain present sampling and make minor additions to better cover nursery areas (e.g., add stations in shallow juvenile habitat). Thus, there is an opportunity for further analyses to determine the feasibility and utility of these surveys for also generating short-term forecasts of recruitment, either as they are presently implemented or with minor changes that do not affect the use of the surveys for other purposes.

When survey-based predictions of recruitment were used in assessments, their apparent accuracy was reasonably high. The $r_{2}$ values averaged 0.76 across all 10 stocks. Such degree of agreement was based on stocks with independent survey and assessment estimates and therefore was not influenced by lack of independence due to use of surveys within assessments. Indeed, for four stocks, survey-based predictions of recruitment were originally independent of the assessments (Table 4). For the six remaining stocks, models were rerun after removing surveybased indices from the assessment. For these six stocks differences between $r_{1}$ and $r_{2}$ depended at least partly on the availability of alternative information on recruitment strength used in stock assessment models. The difference was insignificant for North Sea plaice, for which several alternative data-based sources of information are used in the assessment model to infer prerecruit abundance (including survey-based indices from other surveys; ICES, 2017c). Conversely, $r_{1}-r_{2}$ reached 0.19 for the western Baltic Sea cod, for which recruitment is mainly informed by the survey-based index in the assessment model for young stages (ICES, 2018b). This difference illustrates autocorrelation between survey-based and model-based short-term 
423 forecasts of recruitment; i.e., for stocks where the survey-based recruitment indices informed 424 the assessment models.

The degree of agreement between survey-based and survey-independent, model-based short-term forecasts was not due to a few influential points, as there was an average of 22 years in the various time series. Furthermore, the survey-based predictions out-performed the alternative using a 5-year geometric mean of model-based values.

Given the long history of attempts to predict recruitment in fisheries management, our results strongly suggest that juvenile surveys should be investigated for their potential use in assessments; a theme that has been emphasized by analysis of other stocks (Helle et al., 2000; Zhang et al., 2010; Caputi et al., 2014; Punt, 2019). Any possible use of survey results would need to be evaluated for the specifics of the survey data, the assessment methodology, and the life history of the species.

Deviations between survey-based and model-based short-term forecasts of recruitment may be due to several factors. First is the unknown estimation error in deriving recruitment estimates from surveys due to high spatio-temporal variation in abundance (Denson et al., 2017; Potts and Rose, 2018). Quantifying and understanding the causes of these errors is central to obtaining reliable recruitment estimates (Albert et al., 2001; Ralph and Lipcius, 2014). Second, our assumption that the model-based estimates are accurate ignores how process and estimation errors in recruitment arise from stock assessment models (Hilborn and Walters, 1992). Estimates of recruitment time-series are sensitive to model assumptions used in the assessments (Dickey-Collas et al., 2015). Third, there may be high, density-dependent and variable juvenile mortality (Nash et al., 2007; Le Pape and Bonhommeau, 2015; Haggarty et al., 2017) after the survey-based estimate of pre-recruit abundance. Given that these and other factors add noise to both survey-based and model-based short-term forecasts of recruitment, the degree of 
agreement we found between both predictors across diverse stocks and sampling programs is encouraging.

The small (10 stocks) dataset precluded a comprehensive analysis of the driving factors of survey apparent accuracy. The correlation values did not indicate any obvious dependence on species habitat nor survey design. However, these and other factors, such as life history of the species, probably influence survey accuracy, which warrants analysis with more stocks. Two main issues complicated our ability to determine the factors that influenced the accuracy of survey-based pre-recruit estimates: (i) it is speculative to judge a survey program for generating pre-recruit information when the survey was designed for other purposes, and (ii) our sample size was too small for using the questionnaire results for assessing which factors influence accuracy. Given these caveats, the present analysis allows for some recommendations about survey design to ensure that the surveys provide sufficiently accurate pre-recruit abundance indices for advice about recruitment in stock assessment of species with juvenile coastal dependence:

- Surveys should sample coastal juvenile areas at appropriate times, to avoid the high and variable mortality during the early juvenile stages (Nash et al., 2007; Le Pape and Bonhommeau, 2015; Haggarty et al., 2017).

- Surveys should cover a large proportion of a stock's spatial domain to capture interannual variation in nursery habitat utilization (Albert et al., 2001; Ralph and Lipcius, 2014).

- Surveys should be carried out annually to avoid missing values in the pre-recruit abundance time series.

- The juvenile portion of the survey should include an evaluation of the performance of the sampling gear (e.g., selectivities) and incorporate methods for quantifying variability. 
- Where possible, juvenile surveys or the juvenile component of stock surveys should aim to be as consistent as possible with the survey of non-juvenile areas to provide commensurable data for combined analyses.

These conditions provide a general basis for examining how surveys can be initially evaluated for possible use for juveniles and pre-recruit indices. These recommendations can be applied to situations when surveys are being revised (surveys are presently done for multiple reasons) and new surveys are being designed.

Augmenting the survey-based pre-recruit abundance indices with other covariate variables, such as environmental drivers, may further improve the accuracy of recruitment predictions. Indices based on environmental drivers (e.g., ICES, 2018a for North East Arctic cod; Le Pape et al., 2003 and Lagarde et al., 2018 for Bay of Biscay sole; Denson et al., 2017) alone, or in combination with pre-recruit abundance indices (Zhang et al., 2010; Ralston et al., 2013), could provide helpful information about recruitment trends and variability in the near term. However, changes in total allowable catch (TAC) recommendations lead to gains only when environmental predictors and survey-based pre-recruit abundance indices are accurately assessed (Basson, 1999; De Oliveira and Butterworth, 2005). The increase in accuracy that survey-based pre-recruit abundance indices can provide to catch advice suggests that existing surveys should be evaluated for their potential use.

Predictions of future short-term recruitment can influence management advice both for the assessment year and for the TAC year (ICES, 2015). Our analysis showed that, while a limited number of the total possible stocks that can use survey-based predictions actually use them, when survey-based predictions are used in the assessment their apparent accuracy is reasonable. Survey-based pre-recruit abundance indices are being used for some stocks either explicitly in the stock assessment model (e.g., SAM model; Nielsen and Berg, 2014), or in a separate forecasting routine combined with stock assessment outputs (e.g., RCT3 routine post 
497 XSA model; Shepherd 1997; Shepherd, 1999). These indices inform the expected recruitment 498 in future years. The scope of the present paper was focused on the usefulness of survey-based pre-recruit abundance indices for advice about recruitment, not on the ways in which to utilise these indices in stock assessment procedures; this has been extensively discussed by others 501 (Punt, 2019).

Tools for forecasting recruitment play an important role in fisheries management and decision-making, and all possible tools should be at least explored for their potential utility, if not utilised. When catches are highly dependent on recruitment (short-lived or over-exploited stocks; e.g., North Sea cod, ICES, 2017c), estimating recruitment and possible variability about the forecast is a priority to provide reliable information for management. However, the number of years for which short-term forecasts can benefit from survey-based abundance indices of pre-recruits obviously depend on the year-lag between the first age in the catch forecast and the age of the pre-recruit individuals in the survey. For the large proportion of stocks with only a 1-year lag (Supp. Table 1), there is no observed recruitment survey index for more years ahead, and short-term forecast means a forecast for the next year only.

Even when they are not accounted for in stock assessment, survey-based pre-recruit abundance indices could be considered as quantitative evidence supporting or opposing predictions derived using average previous recruitment, and used to provide a measure of the uncertainty in predicted recruitment. Indeed, when the survey-based pre-recruit abundance indices are not available during an assessment (e.g., Sandeel stocks, sup. Table 1; Table 3),

517 some procedures allow their results to be considered a posteriori. For example, the advice for the main flatfish and round fish stocks in the North Sea has a procedure for reopening after the surveys are conducted in autumn (ICES, 2008; ICES, 2015). Re-evaluating management advice after surveys are completed and pre-recruit abundance indices are estimated to differ

521 significantly from assessment derived indices should make the advice more robust (ICES, 
2008). This procedure of re-evaluating management advice clearly shows the validity and importance of the recruitment indices. We recognize that these approaches introduce additional work for those delivering advice; thus, exploratory analyses to assess their potential benefits to assessments are a good first step. While our focus was on species that use coastal habitats, our evaluation approach is applicable to most species, including those that do not depend on coastal juvenile habitats (Kimoto et al., 2007; Ralston et al., 2013).

We focused our analysis on using existing surveys for stocks that use recruitment forecasts in their assessments. In addition to the use of survey-based pre-recruit abundance indices for forecasting recruitment, fishery-independent surveys can be evaluated for their potential use with other management goals. Examples include quantifying juvenile habitat for informing an ecosystem-based approach to fisheries management (Browman et al., 2004), deriving indices of environmental drivers for further forecasting (Hidalgo et al., 2016), and for informing dynamic marine spatial plans that respond to changes in coastal habitats (Kininmoth et al., 2019). Surveys can also be used to provide alerts on the impacts of anthropogenic disturbances affecting survival of juveniles. A large proportion of coastal-dependent species is impacted by human activity other than fishing mortality when juveniles utilize coastal habitats (Brown et al., 2018a). Regular monitoring of juvenile habitats to provide data for assessment can generate spatially-explicit evidence for local productive areas to inform environmental management. Surveys can provide information on juvenile responses to both environmental drivers (Hermant et al., 2010; Caputi et al., 2014; Lagarde et al., 2018; Brown et al., 2019) and anthropogenic pressures (Rochette et al., 2010; Archambault et al, 2018), which can influence future stock dynamics (Stige et al., 2013). Habitat degradation can result in either overly optimistic or overly conservative assessments of stock status (Brown et al., 2018b). Preserving or restoring the capacity of juvenile habitat is of major importance for improving adult biomass of populations relying on coastal juvenile habitat (Van de Wolfshaar et al., 2011; Le Pape and 
547 Bonhommeau, 2015; Archambault et al., 2018). Existing and planned surveys should be 548 examined for possible leveraging of their results, in addition to their primary motivation and 549 goals, thereby integrating fisheries and ecosystem-based management (Kraufvelin et al., 2018).

\section{Acknowledgements}

552 This work was developed within the context of the ICES working group WGVHES (Working Group on the Value of Coastal Habitats for Exploited Species). The authors thank both ICES and all participants of the working group 2017-2019. The authors also warmly thank Maria

555

Supplementary Material is available at ICES JMS online

\section{References}

Albert, O.T., Nilssen, E.M., Nedreaas, K.H. and Gundersen, A.C. 2001. Distribution and abundance of juvenile North-East Artic Greenland halibut (Reinhardtius hippoglossoides) in relation to survey coverage in the physical environment. ICES Journal of Marine Science 58: 1053-1062. 
573 Archambault, B., Le Pape, O., Bousquet, N. and Rivot, E. 2014. Density dependence can be

574

575

576

577

578

579

580

581

582

583

584

585

586

587

588

589

590

591

592

593

594

595

596

revealed by modeling the variance in the stock-recruitment process. An application to flatfishes. ICES Journal of Marine Science 71: 2127-2140.

Archambault, B., Rivot, E., Savina, M. and Le Pape, O. 2018. Using a spatially structured life cycle model to assess the influence of multiple stressors on an exploited coastal-nurserydependent population. Estuarine Coastal and Shelf Science 201: 95-104.

Basson, M. 1999. The importance of environmental factors in the design of management procedures. ICES Journal of Marine Science 56: 933-942.

Beck, M.W., Heck, K.L., Able, K.W., Childers, D.L., Eggleston, D.B., Gillanders, B.M., Halpern, B., Hays, C.G., Hostino, K., Minello, T.J., Orth, R.J., Sheridan, P., and Weinstein, M.P. 2001. The identification, conservation and management of estuarine and marine nurseries for fish and invertebrates. Bioscience 51: 633-641.

Brown, E.J., Vasconcelos, R.P., Wennhage, H., Bergström, U., Støttrup, J.G., van de Wolfshaar; K., Millisenda, G., Colloca, F. and Le Pape, O. 2018a. Conflicts in the coastal zone: A rapid assessment of human impacts on commercially important fish species utilizing coastal habitat. ICES Journal of Marine Science 75: 1203-1213.

Brown, E.J., Kokkalis, A., Støttrup, J.G. 2019. Juvenile fish habitat across the inner Danish waters: Habitat association models and habitat growth models for European plaice, flounder and common sole informed by a targeted survey. Journal of Sea Research 155: 1-16. 
598 Brown, J.C., Broadley, A., Adame, M.F., Branch, T., Turcschwell, M.P. and Connolly, R.M. 599 2018b, in press. The assessment of fishery status on fish habitats. Fish and Fisheries 20: 1-14.

600

601

602

603

604

605

606

607

608

609

610

611

612

613

614

615

616

617

618

619

620

Browman, H.I., Stergiou, K.I., Cury, P.M., Hilborn, R., Jennings, S., Lotze, H.K., Mace, P.M., Murawski, S., Pauly, D., Sissenwine, M. and Zeller, D. 2004. Perspectives on ecosystem-based approaches to the management of marine resources. Marine Ecology Progress Series 274: 269303.

Caputi, N., de Lestang, S., Hart, A., Kangas, K., Johnston, D., Penn, J. 2014. Catch predictions instock assessment and management of invertebrates fisheries using pre-recruit abundance Case studies from western Australia. Reviews in Fisheries Science \& Aquaculture 22: 36-54.

Cowan, J.H., Rose, K.A. and de Vries, D.R. 2000. Is density dependent growth in young of the year fishes a question of critical weight? Reviews in Fish Biology and Fisheries 10: 61-89.

Cury, P.M., Fromentin, J.M., Figuet, S. and Bonhommeau, S., 2014. Resolving Hjort's dilemma: How is recruitment related to spawning stock biomass in marine fish? Oceanography 27: $42-47$.

De Oliveira, J.A.A. and Butterworth, D.S., 2005. Limits to the use of environmental indices to reduce risk and/or increase yield in the South African anchovy fishery. African Journal of Marine Science 27: 191-203. 
621

622

623

624

625

626

627

628

629

630

631

632

633

634

635

636

637

638

639

640

641

642

643

644

Denson, L.S., Sampson, D.B. and Stephens, A. 2017. Data needs and spatial structure considerations in stock assessments with regional differences in recruitment and exploitation. Canadian Journal of Fisheries and Aquatic Sciences 74: 1918-1929.

Dickey-Collas, M., Hintzen, N.T., Nash, R.D., Schon, P.J., Payne, M.R. 2015. Quirky patterns in time-series of estimates of recruitment could be artefacts. ICES Journal of Marine Science 72: 111-116.

Dingsor, G.E., Cianelli, L., Chan, K.S., Ottersen, G. and Stenset, N.C. 2007. Density dependence and density independence during the early life stages of four marine fish stocks. Ecology 88: 625-634.

Haggarty, D.R., Lotterhos, K.E. and Shurin, J.B. 2017. Young-of-the-year recruitment does not predict the abundance of older age classes in black rockfish in Barkley Sound, British Columbia, Canada. Marine Ecology Progress Series 574: 113-126.

Helle, K., Bogstad, B., Marshall, C.T., Michalsen, K., Ottersen, G. and Pennington, M., 2000. An evaluation of recruitment indices for Arcto-Norwegian cod (Gadus morhua L.). Fisheries Research 48: 55-67.

Hermant, M., Lobry, J., Poulard, J.C., Désaunay, Y., Bonhommeau, S. and Le Pape O. 2010. Impact of warming on abundance and occurrence of flatfish populations in the Bay of Biscay (France). Journal of Sea Research 64: 45-53. 
645 Hilborn, R. and Walters, C. 1992. Quantitative Fisheries Stock Assessment: Choice, Dynamics 646 and Uncertainty. Springer Nature. $570 \mathrm{pp}$.

647

648

Hidalgo, M., Secor, D.H. and Browman, H.I. 2016. Observing and managing seascapes: linking 649 synoptic oceanography, ecological processes, and geospatial modelling. ICES Journal of 650 Marine Science 73: 1825-1830.

651

652

Houde, E.D. 2008. Emerging from Hjort's shadow. Journal of the Northwest Atlantic Fisheries

653 Society 41: 53-70.

654

655

656

(AGCREFA). ICES CM 2008/ACOM: 60.

657

658

ICES. 2012. DLS Guidance Report, ICES Implementation of Advice for Data-limited Stocks 659 in 2012 in its 2012 Advice. ICES Advisory committee. ICES CM 2012/ACOM: 68, 42 pp.

660

661

ICES. 2015. Report of the Benchmark Workshop on North Sea Stocks (WKNSEA), 2-6

662

February 2015, Copenhagen, Denmark. ICES CM 2015/ACOM: 32, 253 pp.

663

664

ICES. 2017a. Report of the Working Group on Widely Distributed Stocks (WGWIDE), 30

August-5 September 2017, ICES Headquarters, Copenhagen, Denmark. ICES CM

666 2017/ACOM: 23, 1111 pp.

667

668

ICES. 2017b. Report of the Working Group on Celtic Seas Ecoregion (WGCSE), 9-18 May 669 2017, Copenhagen, Denmark. ICES CM 2017/ACOM: 13, 1464 pp. 
671 ICES. 2017c. Report of the Working Group on Assessment of Demersal Stocks in the North 672 Sea and Skagerrak (NSSK), 26 April-5 May 2017, ICES HQ. ICES CM 2017/ACOM: 21, 1248 673 pp.

674

675 ICES. 2018a. Report of the Arctic Fisheries Working Group (AFWG), 18-24 April 2018, Ispra, 676 Italy. ICES CM 2018/ACOM: 06, 857 pp.

677

678

ICES. 2018b. Report of the Herring Assessment Working Group for the Area South of $62^{\circ} \mathrm{N}$ 679 (HAWG). 29-31 January 2018 and 12-20 March 2018. ICES HQ, Copenhagen, Denmark. 680 ICES CM 2018/ACOM: 07, 958 pp.

681

682

ICES. 2018c. Report of the North-Western Working Group (NWWG), 26 April-3 May 2018, 683 ICES HQ, Copenhagen, Denmark. ICES CM 2018/ACOM: 09, 733 pp.

684

ICES. 2018d. Baltic Fisheries Assessment Working Group (WGBFAS), 6-13 April 2018, ICES 686 HQ, Copenhagen, Denmark. 727 pp.

687

688

ICES. 2018e. Report of the Working Group for the Bay of Biscay and the Iberian Waters 689 690 Ecoregion (WGBIE), 3-10 May 2018, ICES HQ, Copenhagen, Denmark. ICES CM 2018/ACOM: 12, 642 pp.

691

692

ICES. 2018f. Report of the Working Group on Southern Horse Mackerel, Anchovy and Sardine 693 (WGHANSA) 26-30 June 2018, Lisbon, Portugal. ICES CM 2018/ACOM: 17, 597 pp. 694 
695 ICES. 2018g. ICES Stock Assessment Database. Copenhagen, Denmark. ICES. 2018/01/01. 696 http://standardgraphs.ices.dk.

697

698

Juanes, F. 2007. Role of habitat in mediating mortality during the post-settlement transition 699 phase of temperate marine fishes. Journal of Fish Biology 70: 661-677.

700

701

Kimoto, A., Mouri, T. and Matsuishi, T. 2007. Modelling stock-recruitment relationships to 702 examine stock management policies. ICES Journal of Marine Science 64: 870-877.

703

Kininmonth, S., Weeks, R., Abesamis, R.A., Bernardo, L.P.C., Beger, M., Treml, E.A.,

Williamson, D. and Pressey, R.L. 2019. Strategies in scheduling marine protected area 706 establishment in a network system. Ecological Applications 29: 1-10.

707

708

Kraufvelin, P., Pekcan-Hekim, Z., Bergstrom, U., Florin, A.B., Lehikoinen, A., Mattila, J., 709

Arula, T., Briekmane, L., Brown, E.J., Celmer, Z., Dainys, J., Jokinen, H., Kaaria, P.,

Kallasvuo, M., Lappalainen, A., Lozys, L., Moller, P., Orio, A., Rohtla, M., Saks, L., Snickars, 711 M., Støttrup, G., Sundblad, G., Taal, I., Ustups, D., Verliin, A., Vetemaa, M., Winkler, H., Wozniczka, A. and Olsson, J. 2018. Essential coastal habitats for fish in the Baltic Sea. Estuarine, Coastal and Shelf Science 204: 14-30.

Lagarde, A., Doyen, L., Ahad-Cissé, A., Gourguet, S., Le Pape, O., Thébaud, O., Caill-Milly, N., Morandeau, G. and Macher, C. 2018. How does MMEY mitigate the bioeconomic effects of climate change for mixed fisheries. Ecological Economics 154: 317-332. 
719

720

721

722

723

724

725

726

727

737

Le Pape, O., Chauvet, F., Mahévas, S., Lazure, L., Guérault, G. and Désaunay, Y. 2003. Quantitative description of habitat suitability for the juvenile common sole (Solea solea, L.) and contribution of different habitats to the adult population in the Bay of Biscay (France). Journal of Sea Research 50: 139-149.

Le Pape, O. and Bonhommeau, S. 2015. The food limitation hypothesis for juvenile marine fish. Fish and Fisheries 16: 373-398.

Levin, P.S. and Stunz, G.W. 2005. Habitat triage for exploited fishes: can we identify essential fish habitat? Estuarine, Coastal and Shelf Science 64: 70-78.

Nash, R.D.M., Geffen, A.J., Burrows, M.T. and Gibson, R.N. 2007. Dynamics of shallow-water juvenile flatfish nursery grounds: application of the shelf-thinning rule. Marine Ecology Progress Series 344: 231-244.

Lorenzen, K., and Camp, E.V. 2019. Density-dependence in the life history of fishes: when is a fish recruited? Fisheries Research 217: 5-10.

Needle, C.L. 2001. Recruitment models: diagnosis and prognosis. Reviews in Fish Biology and Fisheries 11: 95-111.

Nielsen, M. and Berg, C. 2014. Estimation of time-varying selectivity in stock assessments using state-space models. Fisheries Research 158: 96-101.

Potts, S.E. and Rose, K.A. 2018. Evaluation of GLM and GAM for estimating population 
744 indices from fishery independent surveys. Fisheries Research 208: 167-178.

745

746

Punt, A.E. 2019. Recruitment: theory, estimation, and application in fishery stock assessment

747

748

749

750

751

752

753

754

755

756

757

758

759

760

761

762

763

764

765

766

767

768

models. Fisheries Research 217: 1-4.

Ralph, G.M. and Lipcius, R.N. 2014. Critical habitats and stock assessment: age-specific bias in the Chesapeake Bay blue crab population survey. Transactions of the American Fisheries Society 143: 889-898.

Ralston, S., Sakuma, K.M. and Field, J.C., 2013. Interannual variation in pelagic juvenile rockfish (Sebastes spp.) abundance-going with the flow. Fisheries Oceanography 22: 288-308.

Rochette, S., Rivot, E., Morin, J., Mackinson, S., Riou, P. and Le Pape O. 2010. Effect of nursery habitat destruction on flatfish population renewal. Application to common sole (Solea solea, L.) in the Eastern Channel (Western Europe). Journal of Sea Research 64: 34-44.

Seitz, R.D., Wennhage, H., Bergstrom, U., Lipcius, R.N. and Ysebaert, T. 2014. Ecological value of coastal habitats for commercially and ecologically important species. ICES Journal of Marine Science 71: 648-655.

Scharf, F. 2000. Patterns in abundance, growth, and mortality of juvenile red drum across estuaries on the Texas coast with implications for recruitment and stock enhancement. Transactions of the American Fisheries Society 129: 1207-1222.

Shepherd, J.G. 1997. Prediction of year-class strength by calibration regression analysis of 
769

770

771

772

773

774

775

776

777

778

779

780

781

782

783

784

785

786

787

788

789

790

791

multiple recruit index series. ICES Journal of Marine Science 54: 741-752.

Shepherd, J.G. 1999. Extended survivors analysis: An improved method for the analysis of catch-at-age data and abundance indices. ICES Journal of Marine Science 56: 584-591.

Sokal, R.R. and Rohlf, F.J. 1995. Biometry. Freeman, New York.

Stige, L.C., Hunsicker, M.E., Bailey, K.M., Yaragina, N.A. and Hunt G.L. 2013. Predicting fish recruitment from juvenile abundance and environmental indices. Marine Ecology Progress Series 480: 245-261.

Szuwalski, C.S., Vert-Pre, K.A., Punt, A.E., Branch, T.A. and Hilborn, R., 2015. Examining common assumptions about recruitment: a meta-analysis of recruitment dynamics for worldwide marine fisheries. Fish and Fisheries 16: 633-648.

van der Veer, H.W., 1986. Immigration, settlement, and density-dependent mortality of a larval and early postlarval 0-group plaice (Pleuronectes platessa) population in the western Wadden Sea. Marine Ecology Progress Series 29, 223-236.

Van de Wolfshaar, K.E., HilleRisLambers, R. and Gardmark, A. 2011. Effect of habitat productivity and exploitation on populations with complex life cycles. Marine Ecology Progress Series 438: 175-184. 
792 Wennhage, H., 2002. Vulnerability of newly settled plaice (Pleuronectes platessa L.) to 793 predation: effects of habitat structure and predator functional response. Journal of 794 Experimental. Marine Biology and Ecology 269, 129-145

795

796 Zhang, T., Bailey, K.M. and Chan, K.S., 2010. Recruitment forecast models for walleye pollock 797 Theragra chalcogramma fine-tuned from juvenile survey data, predator abundance and 798 environmental phase shifts. Marine Ecology Progress Series 417: 237-248. 
Tables legends

801

802

803

804

805

806

807

808

809

810

811

812

813

814

815

Table 1: The 18 species assessed by ICES in 2017-2018 whose juveniles rely on coastal habitats, and their general vertical habitat use (after Seitz et al., 2014 and updated in Brown et al., 2018a).

Table 2: The number of species and stocks assessed by ICES in 2017-2018 based on progressive sub-setting: coastal-dependent, use short-term recruitment forecasts in assessment, existence of surveys with possible estimate of pre-recruitment, and use the survey values as the predictor of recruitment in the assessment.

Table 3: The reasons for rejection, and spatial scale of the survey for the 21 stocks of species that rely on coastal habitats and for which survey-based pre-recruit abundance indices exist but are not presently used in short-term forecasts in ICES assessment.

Table 4: Characteristics of the 14 stocks of species relying on coastal habitats at juvenile stage, for which survey-based pre-recruit abundance indices are used in short-term forecasts in ICES stock assessments. Characteristics shown are: description of the stock, name and information on survey design (*: the selected survey indices for the 2 stocks for which 2 were available), age of pre-recruit in survey-based abundance indices, youngest age in the associated stock assessment, length of the time series, assessment model used, whether the pre-recruit surveybased indices were used in the stock assessment or only for short-term forecasts, the method to eliminate the last two years of the recruitment estimates (either "manually" or "natural, i.e., natural elimination because the last two years were dropped when matching the two recruitment indices"), value of the correlation coefficients $r_{1}$ and $r_{2}\left(r_{2}\right.$ : rerun models (in bold) and stocks 
825 for which survey-indices are not incorporated in the assessment (in italic)).

826

827

828 
Figure legends

831

Figure 1: Number of stocks by DLS Category that used short-term forecasted recruitment in quartiles).

their assessment, categorized by whether a pre-recruit survey exists or not, and if it exists, whether it was used to predict recruitment. A total of 49 stocks were used that were species that rely on coastal habitats and for which ICES assessments used short-term forecasted recruitment.

Figure 2: Scatter plot of survey-based (x axis) and assessment-based (y axis) recruitment (both in the unit used in the stock assessment WG) for the 14 coastal-dependent stocks for which survey-based pre-recruit abundance indices are used as short-term forecasts of recruitment in ICES assessments. Stock codes are defined in Table 4.

Figure 3: Box plot of the correlation coefficients between model-based recruitment indices and (left panel) the geometric mean of the model-based recruitment indices during the last five years $\left(r_{3}\right)$, and (right panel) the survey-based pre-recruit abundance indices $\left(r_{2}\right)$. Each plot is based on the 10 stocks that rely on coastal habitats at juvenile stage and for which the ICES assessments are truly independent from survey-based pre-recruit abundance indices but use these surveybased pre-recruit abundance indices for short-term forecasts of recruitment (thick line, median; box, from the 0.25 quartile to the 0.75 quartile; whiskers, 1.5 times the distance between the 
Table 1: The 18 species assessed by ICES in 2017-2018 whose juveniles rely on coastal habitats, and their general vertical habitat use (after Seitz et al., 2014 and updated in Brown et al., 2018a).

\begin{tabular}{|l|l|}
\hline \multicolumn{1}{|c|}{ Species } & Vertical position \\
\hline & \\
\hline Ammodytes & Demersal \\
\hline Anguilla anguilla & Demersal \\
\hline Clupea harengus & Pelagic \\
\hline Dicentrarchus labrax & Demersal \\
\hline Engraulis encrasicolus & Pelagic \\
\hline Gadus morhua & Demersal \\
\hline Limanda limanda & Benthic \\
\hline Merlangius merlangus & Demersal \\
\hline Mullus surmuletus & Demersal \\
\hline Platichthys flesus & Benthic \\
\hline Pleuronectes platessa & Benthic \\
\hline Pollachius pollachius & Demersal \\
\hline Pollachius virens & Demersal \\
\hline Psetta maxima (historic name) & Benthic \\
\hline Scomber scombrus & Pelagic \\
\hline Scophthalmus rhombus & Benthic \\
\hline Solea solea & Benthic \\
\hline Sprattus sprattus & Pelagic \\
\hline
\end{tabular}


Table 2: The number of species and stocks assessed by ICES in 2017-2018 based on progressive sub-setting: coastal-dependent, use short-term recruitment forecasts in assessment, existence of surveys with possible estimate of pre-recruitment, and use the survey values as the predictor of recruitment in the assessment.

\begin{tabular}{|l|r|c|}
\hline \multicolumn{1}{|c|}{ Category } & Number of species & Number of stocks \\
\hline ICES evaluated & 61 & 185 \\
\hline \& coastally-dependent juveniles & 18 & 78 \\
\hline \& with short-term forecast & & 49 \\
\hline \& with potential existing survey based pre-recruit indices & & 35 \\
\hline \& using survey-based indices in forecast & & 14 \\
\hline
\end{tabular}


Table 3: The reasons for rejection, and spatial scale of the survey for the 21 stocks of species that rely on coastal habitats and for which survey-based pre-recruit abundance indices exist but are not presently used in short-term forecasts in ICES assessment.

\begin{tabular}{|l|c|l|}
\hline \multicolumn{1}{|c|}{ Reason to reject } & Number of stocks & \multicolumn{1}{c|}{ Scale of the survey } \\
\hline Incomplete time-series & 2 & \\
\hline Too late to be used & 4 & \\
\hline Not investigated, nor tested & 11 & $\begin{array}{l}\text { Stock scale, not including nurseries (2) } \\
\text { Stock distribution partially covered, including coastal nurseries (6) } \\
\text { Stock distribution partially covered, not including coastal nurseries (3) }\end{array}$ \\
\hline Investigated and rejected & 4 & $\begin{array}{l}\text { Stock distribution partially covered, including coastal nurseries (2) } \\
\text { Stock distribution partially covered, not including coastal nurseries (2) }\end{array}$ \\
\hline
\end{tabular}




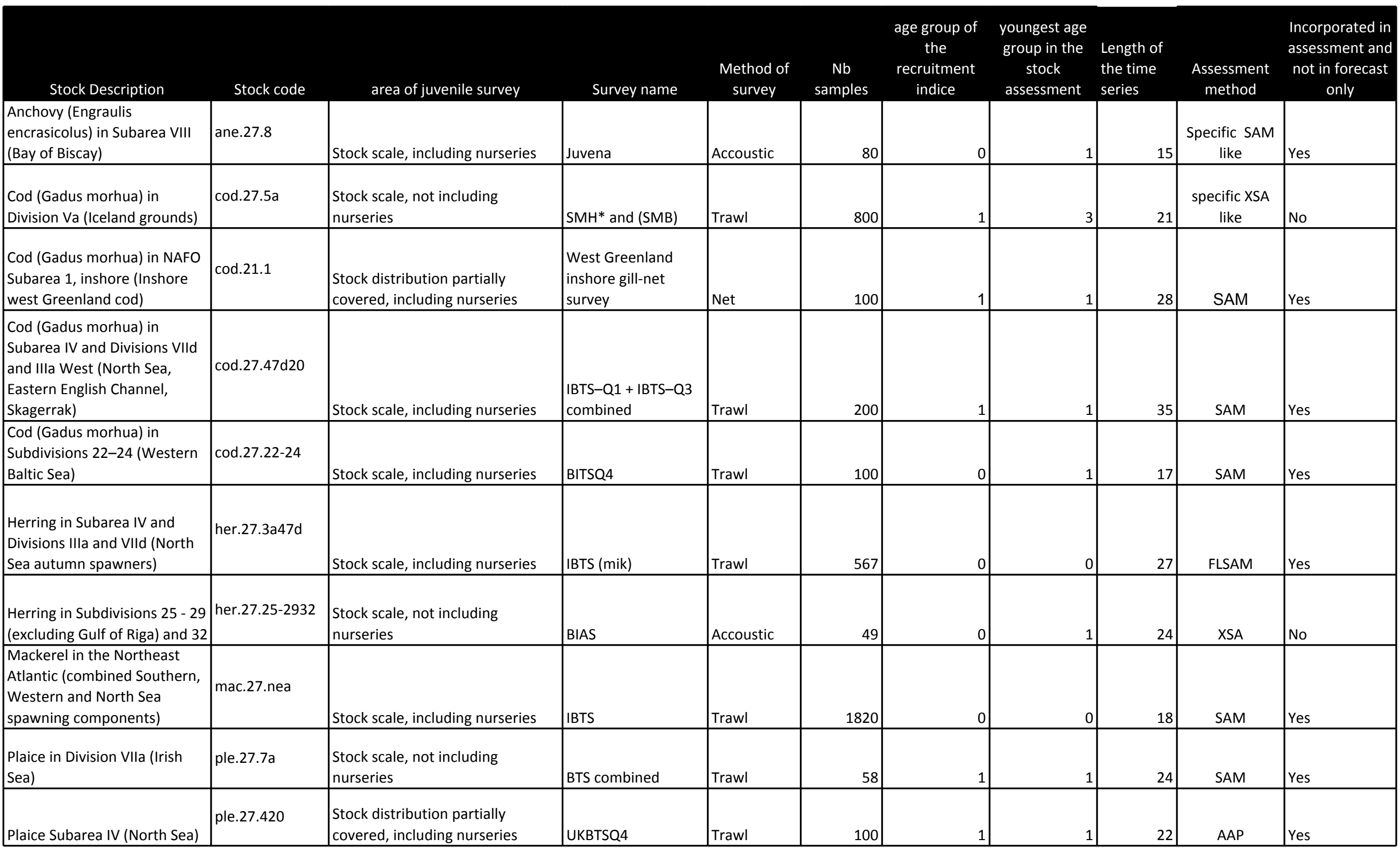




\begin{tabular}{|c|c|c|c|c|c|c|c|c|c|c|}
\hline Sole in Subarea IV (North Sea) & sol.27.4 & $\begin{array}{l}\text { Stock distribution partially } \\
\text { covered, including nurseries }\end{array}$ & DFS combined & Trawl & 630 & 0 & 1 & 26 & AAP & No \\
\hline \begin{tabular}{|l}
$\begin{array}{l}\text { Sprat in Subdivisions } 22-32 \\
\text { (Baltic Sea) }\end{array}$ \\
\end{tabular} & spr.27.22-32 & Stock scale, including nurseries & BIAS & Accoustic & & 0 & 1 & 23 & XSA & No \\
\hline $\begin{array}{l}\text { Whiting in ICES Division VIIlb, } \\
\text { c, e-k }\end{array}$ & whg.27.7b-ce-k & $\begin{array}{l}\text { Stock distribution partially } \\
\text { covered, including nurseries }\end{array}$ & $\begin{array}{l}\text { IGFS+EVHOE } \\
\text { Combined indice }\end{array}$ & Trawl & 180 & 0 & 0 & 14 & XSA & Yes \\
\hline $\begin{array}{l}\text { Whiting Subarea IV (North } \\
\text { Sea) and Division VIId (Eastern } \\
\text { Channel) }\end{array}$ & whg.27.47d & Stock scale, including nurseries & $\begin{array}{l}\text { IBTSQ3* and } \\
\text { (IBTSQ1) }\end{array}$ & Trawl & 310 & 1 & $1 *$ & 26 & XSA & Yes \\
\hline
\end{tabular}




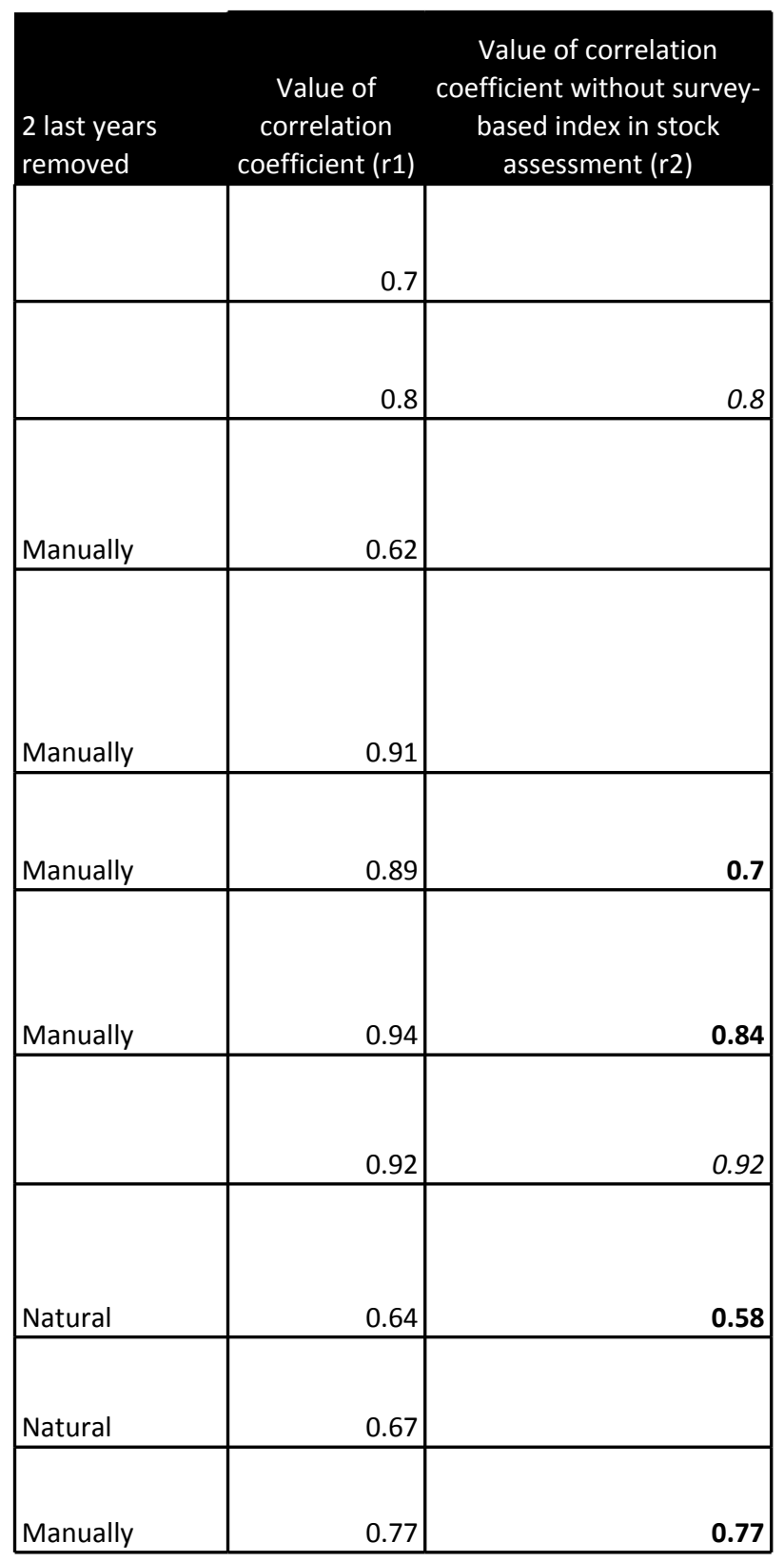




\begin{tabular}{|l|r|r|}
\hline & 0.83 & 0.83 \\
\hline & 0.85 & 0.85 \\
\hline Natural & 0.79 & $\mathbf{0 . 6 8}$ \\
\hline & & \\
\hline & 0.67 & 0.67 \\
\hline
\end{tabular}




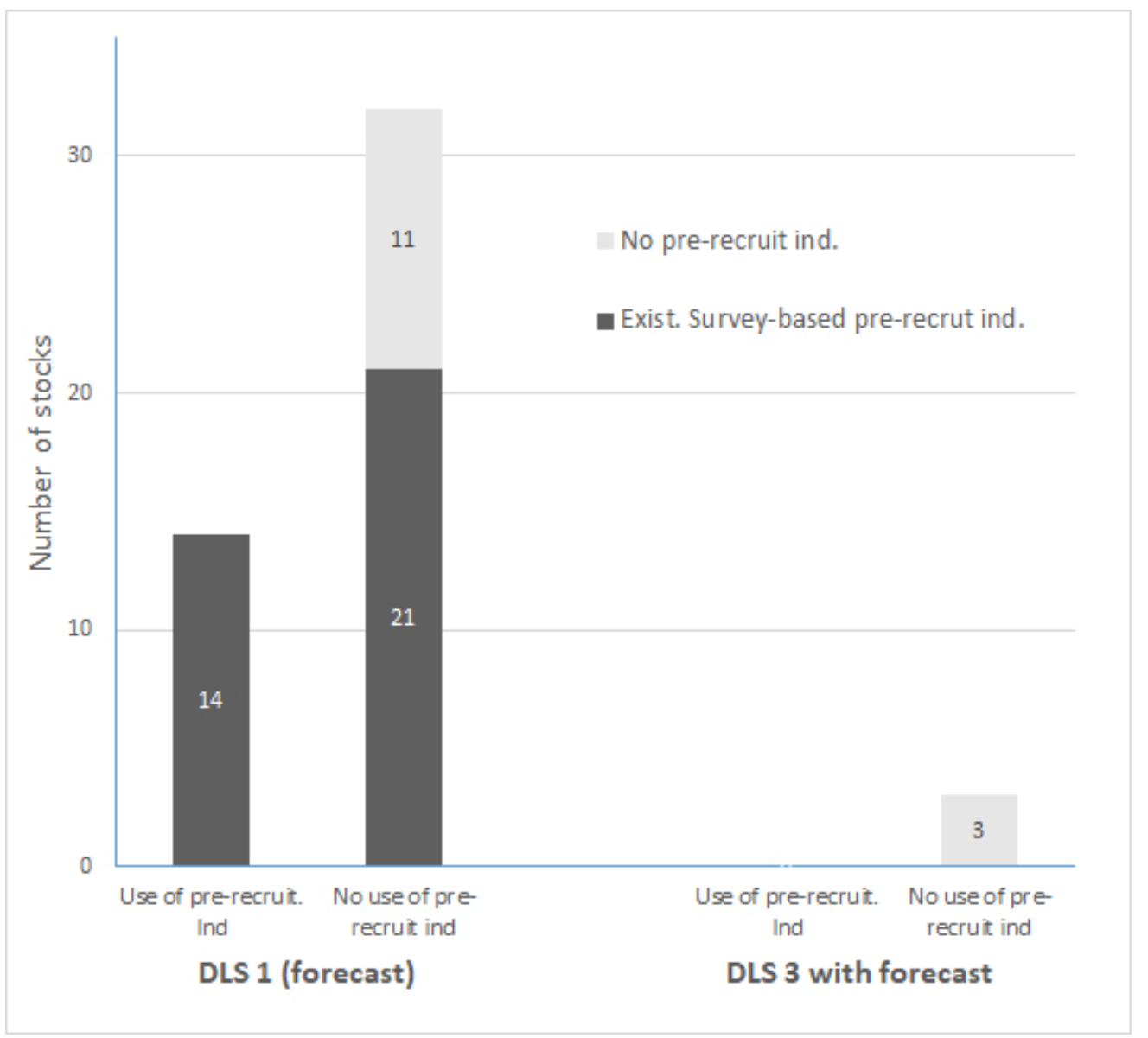

Figure 1: Number of stocks by DLS Category that used short-term forecasted recruitment in their assessment, categorized by whether a pre-recruit survey exists or not, and if it exists, whether it was used to predict recruitment. A total of 49 stocks were used that were species that rely on coastal habitats and for which ICES assessments used short-term forecasted recruitment. 


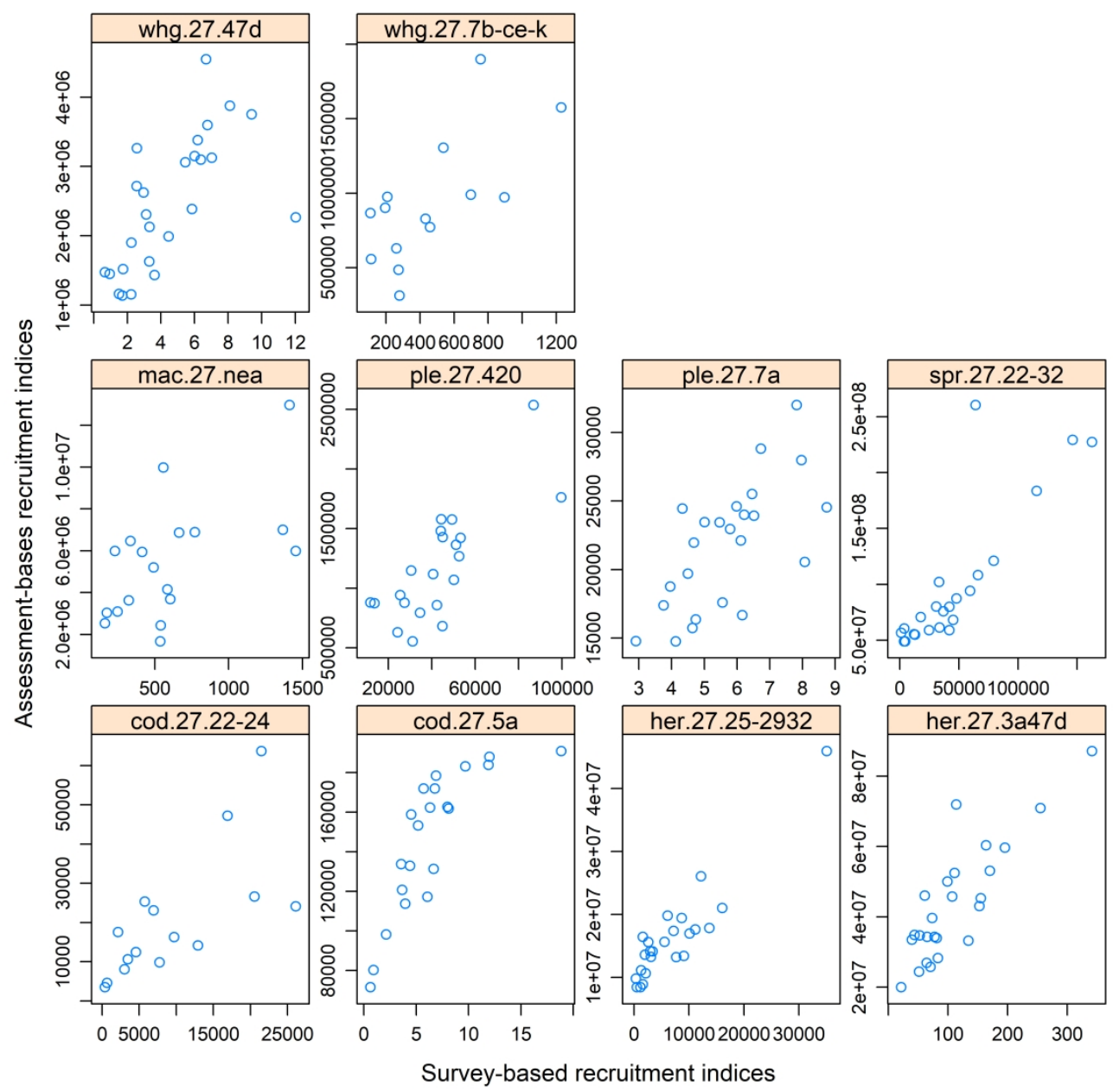

Figure 2: Scatter plot of survey-based (x axis) and assessment-based (y axis) recruitment (both in the unit used in the stock assessment WG) for the 14 coastal-dependent stocks for which survey-based pre-recruit abundance indices are used as short-term forecasts of recruitment in ICES assessments. Stock codes are defined in Table 4. 

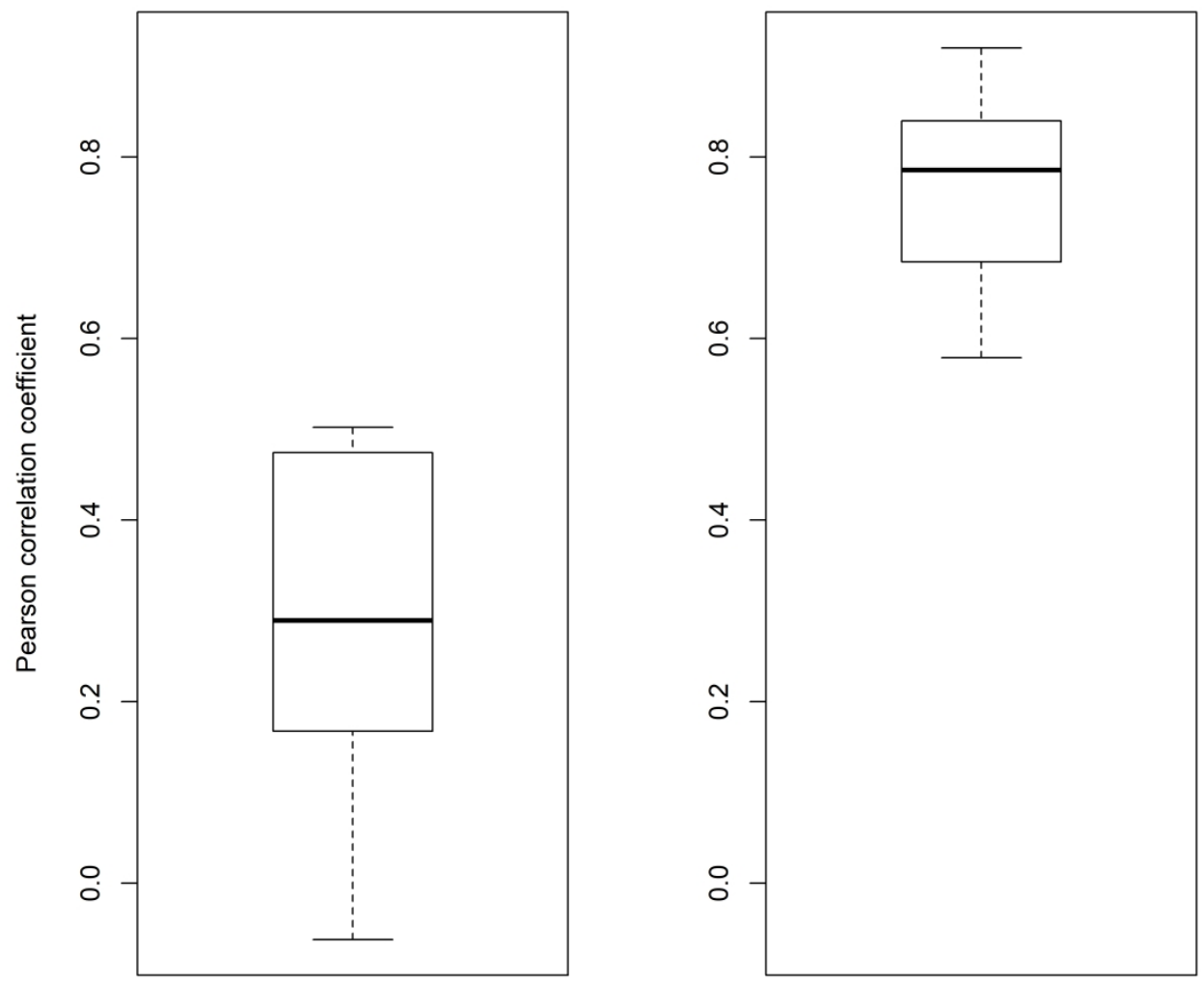

Figure 3: Box plot of the correlation coefficients between model-based recruitment indices and (left panel) the geometric mean of the model-based recruitment indices during the last five years ( $r 3$ ), and (right panel) the survey-based pre-recruit abundance indices (r2). Each plot is based on the 10 stocks that rely on coastal habitats at juvenile stage and for which the ICES assessments are truly independent from survey-based prerecruit abundance indices but use these survey-based pre-recruit abundance indices for short-term forecasts of recruitment (thick line, median; box, from the 0.25 quartile to the 0.75 quartile; whiskers, 1.5 times the distance between the quartiles). 